\title{
The effect of race on survival after local therapy in metastatic prostate cancer patients
}

Elio Mazzone ${ }^{1}$; Marco Bandini ${ }^{1,2}$; Felix Preisser $^{3}$; Sebastiano Nazzani ${ }^{2}$; Zhe Tian²; Firas Abdollah ${ }^{4}$; Denis Soulieres $^{5}$; Markus Graefen ${ }^{6}$; Francesco Montorsi ${ }^{1}$; Shahrokh Shariat ${ }^{7}$; Fred Saad ${ }^{2}$; Alberto Briganti $^{1}$; Pierre Karakiewicz ${ }^{2}$

${ }^{1}$ Division of Oncology/Unit of Urology, URI, IRCCS Ospedale San Raffaele and Vita-Salute San Raffaele University, Milan, Italy; ${ }^{2}$ Cancer Prognostics and Health Outcomes Unit, University of Montreal Health Centre, Montreal, QC, Canada; ${ }^{3}$ Department of Urology, Goethe-Universität Frankfurt am Main, Germany; ${ }^{4}$ Henry Ford Health System, Detroit , MI, United States; ${ }^{5}$ Division of Medical Oncology/Hematology Centre Hospitalier de l’Université de Montréal, Montreal, QC, Canada; ${ }^{6}$ Martini-Clinic, Prostate Cancer Centre Hamburg-Eppendorf, Hamburg, Germany; ${ }^{7}$ Department of Urology, Medical University of Vienna, Vienna, Austria

Cite as: Can Urol Assoc J 2018 October 15; Epub ahead of print. http://dx.doi.org/10.5489/cuaj.5399

Published online October 15, 2018

$* * *$

\section{Abstract}

Introduction: Local therapy (LT) may offer a survival advantage in highly select newly diagnosed metastatic prostate cancer (mPCa) patients. However, it is unknown whether the benefits vary according to Caucasian vs. African American (AA) patients.

Methods: Within the Surveillance Epidemiology and End Results database (2004-2014), we focused on Caucasians and AA patients with newly diagnosed mPCa treated with LT: radical prostatectomy (RP) and brachytherapy (RT). Endpoints consisted of cancer-specific mortality (CSM) and overall mortality (OM). Kaplan-Meier analyses and multivariable Cox regression models tested for racial difference in CSM and OM.

Results: Between 2004 and 2014, we identified 408 (77.2\%) Caucasians and 121 (22.8\%) AAs with newly diagnosed mPCa treated with LT: either RP $(n=357)$ or RT $(n=172)$. According to race, when LT is defined as RP, Caucasian patients had a significantly longer survival vs. AA patients: CSM-free survival 123 vs. 63 months ( $\mathrm{p}=0.004$ ) and OM-free survival 108 vs. 46 months ( $\mathrm{p}=0.002$ ). The CSM and OM benefits were confirmed in multivariable analyses (hazard ratio [HR] 0.56, $\mathrm{p}=0.01$ for CSM; HR 0.60, $\mathrm{p}=0.01$ for OM). However, no differences in CSM or OM were recorded according to race when $\mathrm{LT}$ consisted of $\mathrm{RT}$.

Conclusions: Our results indicate that race is not associated with difference in survival after LT in mPCa patients. However, when focusing on RP-treated patients, Caucasian race is associated with higher CSM and OM rates relative to AA race. This racial difference does not apply to RT. Our findings should be considered in future prospective trials for the purpose of pre-planned stratification according to race. 


\section{Introduction}

Local therapy (LT) may offer a survival advantage in highly select patients with newly diagnosed metastatic prostate cancer (mPCa) according to several retrospective studies $\left[{ }^{1-10}\right]$. Nonetheless, the retrospective nature of these studies requires prospective validation. Indeed, the ongoing g-RAMPP trial $\left[{ }^{11}\right]$ will provide European data. Similarly, the upcoming SWOG-1802 trial $\left[{ }^{12}\right]$ and other trials will provide North American data. To the best of our knowledge, no ongoing study is sufficiently powered to allow pre-planned stratification according to race $\left[{ }^{11,12}\right]$. Similarly, we are unaware of previous studies that examined the effect of race in retrospective analyses.

In the light of these limitations, our goal was to test the effect of race on cancer specific mortality (CSM) and overall mortality (OM) in patients treated with LT, in the context of newly diagnosed mPCa. Specifically, we hypothesized that the survival benefit of LT may be different according to race (Caucasian vs AA), since AA patients may harbour more aggressive prostate cancer characteristics than their Caucasian counterparts $\left[{ }^{13-21}\right]$. Moreover, we performed separate analyses for radical prostatectomy (RP) and brachytherapy (RT), based on previously reported differences in the survival benefit, according to LT type $\left[{ }^{6}\right]$.

\section{Methods}

\section{Data source and patient selection}

The current study relied on the Surveillance Epidemiology and End Results (SEER) database (2004-2014), which samples 26\% of the United States and approximates the United States in terms of demographic composition, as well as of cancer incidence $\left[{ }^{22}\right]$. In the SEER database, we focused on Caucasian and AA men aged 18 years or older, diagnosed between 2004 and 2014 with histologically confirmed adenocarcinoma of the prostate (International Classification of Disease for Oncology [ICD-O-3] code 8140 site code C61.9). We only considered patients with newly diagnosed mPCa. CSM was defined according to the SEER mortality code. All other deaths were considered as other-cause mortality (OCM). LT types available in SEER database consist of: 1) radical prostatectomy (RP) (surgery site codes 50 and 70) with or without external beam radiation therapy (EBRT) or (2) RT (ie, brachytherapy) with or without EBRT [ ${ }^{6}$ ]. Brachytherapy was defined as prostate-directed radioactive implants with ("Combination of beam with implants or isotopes" according to "Radiation.recode” SEER variable) or without ("Radioactive implant" or "Radioisotopes" according to "Radiation.recode" SEER variable) combined administration of EBRT. EBRT was excluded due to the lack of data regarding target site that allows to distinguish local from extraprostatic treatment $\left[^{6}\right]$. Other surgical treatments than RP were also excluded, as described earlier $\left[^{6}\right]$. These selection criteria yielded 529 patients, who were addressed in overall analysis of the effect of LT (RP and RT) according to race. Subsequently, analyses were repeated according to LT type: one set of analyses focused on RP patients and another set of analyses focused on RT patients.

\section{Statistical analyses and covariates}

Kaplan-Meier (KM) and Cox regression model (CRM) were fitted to evaluate CSM and OM. Race represented the risk variable of interest. In multivariable CRM, adjustment variables consisted of age at diagnosis, prostate-specific antigen (PSA), year of diagnosis, marital status (married, unmarried, unknown), biopsy Gleason score (GS) at diagnosis, clinical stage (cT), clinical lymph node stage (cN0, cNx, cN1) and M1 sub-stage (according to the sixth (2004-2009) and seventh (2010-2014) edition of American Joint Committee on Cancer [AJCC] Cancer Staging Manual 
[M1a, M1b, M1c]) $\left.{ }^{23}\right]$. Medians and ranges were reported for continuously coded variables (age and PSA). The statistical significance of differences in medians and proportions was tested with Kruskal-Wallis and chi-square tests. All statistical tests were two-sided with a level of significance set at $\mathrm{p}<0.05$. Analyses were performed using the R software (version 3.3.0; http://www.rproject.org/).

\section{Results}

\section{General characteristics of the study populations}

Overall, we identified 529 men with newly diagnosed mPCa treated with LT between 2004-2014. Of these, 408 (77.2\%) were Caucasian and 121 (22.8\%) were AA. AA patients had higher median PSA level at diagnosis (18.2 vs. $13.4 \mathrm{ng} / \mathrm{ml}, \mathrm{p}=0.018)$ and were more frequently unmarried $(41.3 \%$ vs. $22.5 \%, \mathrm{p}<0.001)$ than Caucasian. Median age at diagnosis was virtually the same between the two groups (65 years for both, $\mathrm{p}=0.3$ ). According to clinical AJCC M sub-staging, AAs more frequently harboured M1c stage (26.4\% vs. 20.3\%, p=0.017). RP was performed in 283 (69.4\%) Caucasians and 74 (61.2\%) AAs. Similarly, RT was performed in 125 (30.6\%) Caucasians and 47 (38.8\%) AAs (Table 1).

\section{Survival analyses}

In the overall population consisting of RP and RT patients, KM analyses demonstrated CSM free survival of 123 months for Caucasians versus 117 months for AAs $(p=0.1)$. Similarly, OM free survival was 82 months for Caucasians versus 57 months for AAs ( $p=0.07$ ) (Fig. 1A). In multivariable analyses, no differences were reported according to race in model that focused on CSM (HR 0.71, CI 0.49-1.03, $\mathrm{p}=0.07$ ), as well as in the model that focused on OM (HR 0.75, CI 0.54-1.04, $\mathrm{p}=0.09$ ) (Table 2).

In patients treated with RP, unadjusted KM analyses demonstrated CSM free survival of 123 months for Caucasians versus 63 months for AAs ( $\mathrm{p}=0.004$ ), and OM free survival of 108 months for Caucasians versus 46 months for AAs ( $p=0.002$ ) (Fig.1B). In multivariable Cox regression models, stratification according to Caucasian vs AA race resulted in HR 0.56 (CI 0.35-0.88, $\mathrm{p}=0.01$ ). Similarly, in multivariable models predicting $\mathrm{OM}$, stratification according to Caucasian vs AA race resulted in HR 0.66 (CI 0.40-0.90, p=0.01) (Table 3).

In RT patients, unadjusted KM analyses showed that median CSM free survival was 82 months for Caucasians and was not reached for AAs ( $p=0.4)$. Similarly, OM free survival was 64 months for Caucasians versus 68 months for AAs ( $p=0.4$ ) (Fig. 1C). In multivariable analyses, no differences were identified according to race in models that focused on CSM (HR 1.25, CI 0.622.50, $\mathrm{p}=0.5$ ), as well as in models that focused on OM (HR 1.21, CI 0.67-2.17, p=0.5) (Table 4).

\section{Discussion}

In the context of newly diagnosed mPCa, LT has been shown to improve overall survival in several retrospective epidemiological analyses $\left[{ }^{1-6,9,10}\right]$. We hypothesized that AA patients may be associated with lower CSM and OM rates after LT relative to their Caucasian counterparts in the context of mPCa, based on previous evidence suggesting a more aggressive PCa phenotype in AAs $\left[{ }^{13-18}\right]$. We also postulated that the survival benefit from LT may differ according to LT type: RP versus RT $\left.{ }^{2,3,6}\right]$. To address this hypothesis, we examined the effect of race on CSM and OM in patients with mPCa treated with LT, that consisted of either RP or RT. Our study yielded several noteworthy findings. 
First, CSM and OM did not differ between Caucasian and AA patients when LT was defined as either RP and RT. Absence of differences was recorded in both unadjusted and fully adjusted analyses. This finding is consistent with previous studies that examined the effect of LT in the context of mPCa, where LT was defined as either RP and RT [ $\left.{ }^{3,6}\right]$.

However, when LT was defined as only RP, OM and CSM analyses showed important survival differences according to race. Specifically, AA patients exhibited worse survival in both CSM and OM analyses. Subsequent analyses that exclusively focused on RT patients failed to demonstrate racial differences in CSM and OM, in both unadjusted and adjusted models. Taken together, these findings illustrate two important points. Our data suggest that racial differences may be associated with survival differences after LT in the context of newly diagnosed mPCa. Our retrospective observations also suggest that a potential survival benefit according to Caucasian race may only apply to LT defined as RP, but not to RT.

These findings have important clinical implications. Until prospective randomized trials of LT in mPCa context become available with pre-planned stratification according to race, our retrospective analysis seems to show a different association between survival and RP according to race. This recommendation needs to be accompanied by a warning about potential flaws originating from retrospective analyses.

Our findings also need to be considered, when the type of LT is debated in the context of the mPCa in AA patients. According to previously reported data $\left[{ }^{2-6,9}\right]$, RT did show a survival benefit in retrospective survival analyses focusing on newly diagnosed mPCa. In several of these analyses, RT appeared to provide a benefit that was of lesser magnitude than that derived from RP $\left.{ }^{2,3,6}\right]$. Our findings add to the existing evidence and suggest no racial differences in survival, when RT is contemplated. In consequence, until randomized prospective trials examining the effect of LT on survival in mPCa become available, the results of the current analysis may help to better address the use of RP or RT according to race in highly select mPCa patients who are candidate to receive LT.

Second, regarding the survival benefit observed after RP in the context of $\mathrm{mPCa}$, the advantage recorded in Caucasian patients requires special consideration. All analyses relied on two separate outcomes: CSM and OM. In both analyses (CSM and OM), virtually the same results were observed. This observation indicates that RP in newly diagnosed MPCa has a robust beneficial effect in Caucasian patients, when either CSM or OM are examined. Similarities in CSM and OM imply that RP delivered to newly diagnosed metastatic Caucasian patients not only results in more favourable CSM, but also results in more favourable OM (HR 0.56, $\mathrm{p}=0.01$ for CSM; HR 0.6, $\mathrm{p}=0.01$ for $\mathrm{OM}$ ).

Third, we confirmed the prognostic significance of several established risk variables in newly diagnosed mPCa patients. These variables consisted of biopsy GS, clinical T stage and PSA. These observations confirm the validity of our models with respect to disease aggressiveness, according to stage and grade.

Our study is not devoid of limitations. First, it is affected by its retrospective nature, as applicable to previous analyses $\left[{ }^{1-6,9,10}\right]$. Second, we are not able to assess the exact extent of the metastatic disease, despite adjustment for AJCC M1 sub-stages. For example, we had no data regarding specific number or location of metastatic foci beyond the information conveyed by M1 sub-stages. Third, as in several previous analyses $\left[{ }^{2-4,6}\right]$, we were unable to adjust for baseline comorbidities. To address these limitations, we performed analyses focusing on OM, and not only in CSM. Analyses of both end-points provided virtually the same results. This implies a marginal confounding effect of comorbidities, if any. Fourth, data regarding additional systemic treatments is 
not available in the SEER registry. Finally, the number of AA patients, who benefited from LT, was limited. This may have affected the statistical significance of our comparisons. However, the findings regarding racial differences in RP patients were both highly clinically meaningful and highly statistically significant. This implies that sample size did not undermine comparisons of survival according to race in RP patients. Regarding comparisons according to race in RT patients, the sample size was indeed more limited. However, the recorded absolute figures and rates were virtually the same between the two races. This suggests that lack of survival difference in RT patients is unlikely directly related to sample size limitations.

\section{Conclusion}

Our results indicate that race is not associated with difference in survival after LT in mPCa patients. When focusing on RP treated patients, Caucasian race is associated with higher CSM and OM rates relative to African-American race. However, the effect of RT appears unrelated to race and virtually the same absolutes findings were recorded in Caucasian and AA patients. 


\section{References}

1. Gratzke C, Engel J, Stief CG. Role of radical prostatectomy in metastatic prostate cancer: Data from the munich cancer registry. Eur Urol. 2014;66(3):602-603. doi:10.1016/j.eururo.2014.04.009

2. Culp SH, Schellhammer PF, Williams MB. Might men diagnosed with metastatic prostate cancer benefit from definitive treatment of the primary tumor? A SEER-based study. Eur Urol. 2014;65(6):1058-1066. doi:10.1016/j.eururo.2013.11.012

3. Antwi S, Everson TM. Prognostic impact of definitive local therapy of the primary tumor in men with metastatic prostate cancer at diagnosis: A population-based, propensity score analysis. Cancer Epidemiol. 2014;38(4):435-441. doi:10.1016/j.canep.2014.04.002

4. Fossati N, Trinh QD, Sammon J, et al. Identifying optimal candidates for local treatment of the primary tumor among patients diagnosed with metastatic prostate cancer: A SEER-based Study. Eur Urol. 2015;67(1):3-6. doi:10.1016/j.eururo.2014.08.056

5. Löppenberg B, Dalela D, Karabon P, et al. The Impact of Local Treatment on Overall Survival in Patients with Metastatic Prostate Cancer on Diagnosis: A National Cancer Data Base Analysis. Eur Urol. 2017;72(1):14-19. doi:10.1016/j.eururo.2016.04.031

6. Leyh-Bannurah SR, Gazdovich S, Budäus L, et al. Local Therapy Improves Survival in Metastatic Prostate Cancer. Eur Urol. 2017;72(1):118-124. doi:10.1016/j.eururo.2017.03.020

7. Gandaglia G, Fossati N, Stabile A, et al. Radical Prostatectomy in Men with Oligometastatic Prostate Cancer: Results of a Single-institution Series with Long-term Follow-up. Eur Urol. 2017;72(2):289-292. doi:10.1016/j.eururo.2016.08.040

8. Heidenreich A, Pfister D, Porres D. Cytoreductive Radical Prostatectomy in Patients with Prostate Cancer and Low Volume Skeletal Metastases: Results of a Feasibility and CaseControl Study. J Urol. 2018;193(3):832-838. doi:10.1016/j.juro.2014.09.089

9. Satkunasivam R, Kim AE, Desai M, et al. Radical prostatectomy or external beam radiation therapy versus no local therapy for survival benefit in metastatic prostate cancer - a SEERMedicare analysis. J Urol. 2015;194(2):378-385. doi:10.1016/j.juro.2015.02.084.Radical

10. Sooriakumaran P, Karnes J, Stief C, et al. A Multi-institutional Analysis of Perioperative Outcomes in 106 Men Who Underwent Radical Prostatectomy for Distant Metastatic Prostate Cancer at Presentation. Eur Urol. 2016;69(5):788-794. doi:10.1016/j.eururo.2015.05.023

11. Impact of Radical Prostatectomy as Primary Treatment in Patients With Prostate Cancer With Limited Bone Metastases (g-RAMPP). https://clinicaltrials.gov/ct2/show/NCT02454543?term=NCT02454543\&rank=1.

12. Best Systemic Therapy or Best Systemic Therapy (BST) Plus Definitive Treatment (Radiation or Surgery). https://clinicaltrials.gov/ct2/show/study/NCT01751438?term=NCT01751438\&rank=1.

13. Chornokur G, Dalton K, Borysova M, Kumar N. Disparities at Presentation, Diagnosis, Treatment and Survival in African American Men, Affected by Prostate Cancer. Prostate. 2011;71(9):985-997. doi:10.1002/pros.21314

14. Yamoah K, Walker A, Spangler E, et al. African-American race is a predictor of seminal vesicle invasion following radical prostatectomy. Clin Genitourin Cancer. 2015;13(2):e65e72. doi:10.1016/j.clgc.2014.08.012

15. Yamoah K, Johnson MH, Choeurng V, et al. Novel Biomarker Signature That May Predict 
Aggressive Disease in African American Men With Prostate Cancer. J Clin Oncol. 2015;33(25):2789-2796. doi:10.1200/JCO.2014.59.8912

16. Lindquist KJ, Paris PL, Hoffmann TJ, et al. Mutational landscape of aggressive prostate tumors in African American men. Cancer Res. 2016;76(7):1860-1868. doi:10.1158/00085472.CAN-15-1787

17. Shiina M, Hashimoto Y, Kato T, et al. Differential expression of miR-34b and androgen receptor pathway regulate prostate cancer aggressiveness between African-Americans and Caucasians. Oncotarget. 2017;8(5):8356-8368. doi:10.18632/oncotarget.14198

18. Woods-Burnham L, Basu A, Cajigas-Du Ross CK, et al. The 22Rv1 prostate cancer cell line carries mixed genetic ancestry: Implications for prostate cancer health disparities research using pre-clinical models. Prostate. 2017;77(16):1601-1608. doi:10.1002/pros.23437

19. Freedland SJ, Vidal AC, Howard LE, et al. Race and risk of metastases and survival after radical prostatectomy: Results from the SEARCH database. Cancer. 2017;123(21):41994206. doi:10.1002/cncr.30834

20. Steele CB, Li J, Huang B, Weir HK. Prostate cancer survival in the United States by race and stage (2001-2009): Findings from the CONCORD-2 study. Cancer. 2017;123(i):5160-5177. doi:10.1002/cncr.31026

21. Zeng C, Wen W, AK M, Pao W, Shu X, Zheng W. Disparities by race, age, and sex in the improvement of survival for major cancers: Results from the national cancer institute surveillance, epidemiology, and end results (seer) program in the united states, 1990 to 2010. JAMA Oncol. 2015;1(1):88-96. http://dx.doi.org/10.1001/jamaoncol.2014.161.

22. Noone A-M, Cronin KA, Altekruse SF, et al. Cancer Incidence and Survival Trends by Subtype Using Data from the Surveillance Epidemiology and End Results Program, 19922013. Cancer Epidemiol Biomarkers Prev. 2017;26(4):632-641. doi:10.1158/1055-9965.EPI16-0520

23. Edge SB, Compton CC. The american joint committee on cancer: The 7th edition of the AJCC cancer staging manual and the future of TNM. Ann Surg Oncol. 2010;17(6):14711474. doi:10.1245/s10434-010-0985-4 
Fig. 1._Kaplan-Meier plots: cancer-specific mortality (CSM)-free survival (left column) and overall mortality (OM)-free survival (right column) of 529 Caucasian and African American (AA) patients with newly diagnosed metastatic prostate cancer, stratified according to local therapy type. CI: confidence interval.

A
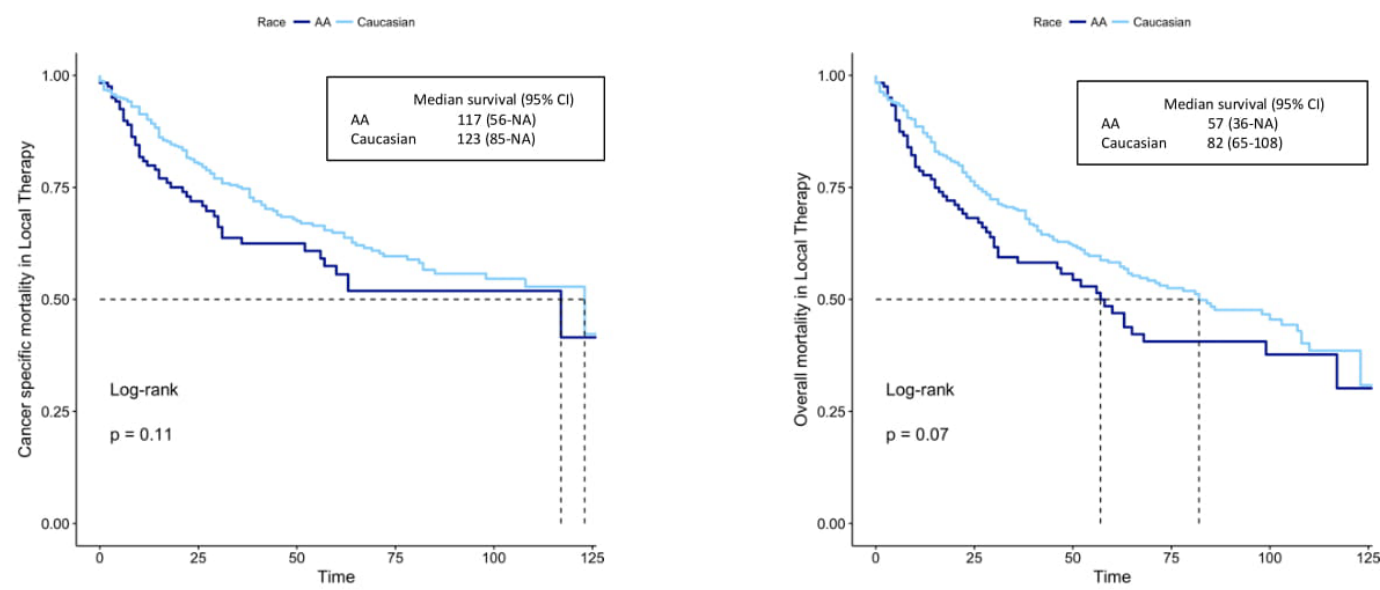

B
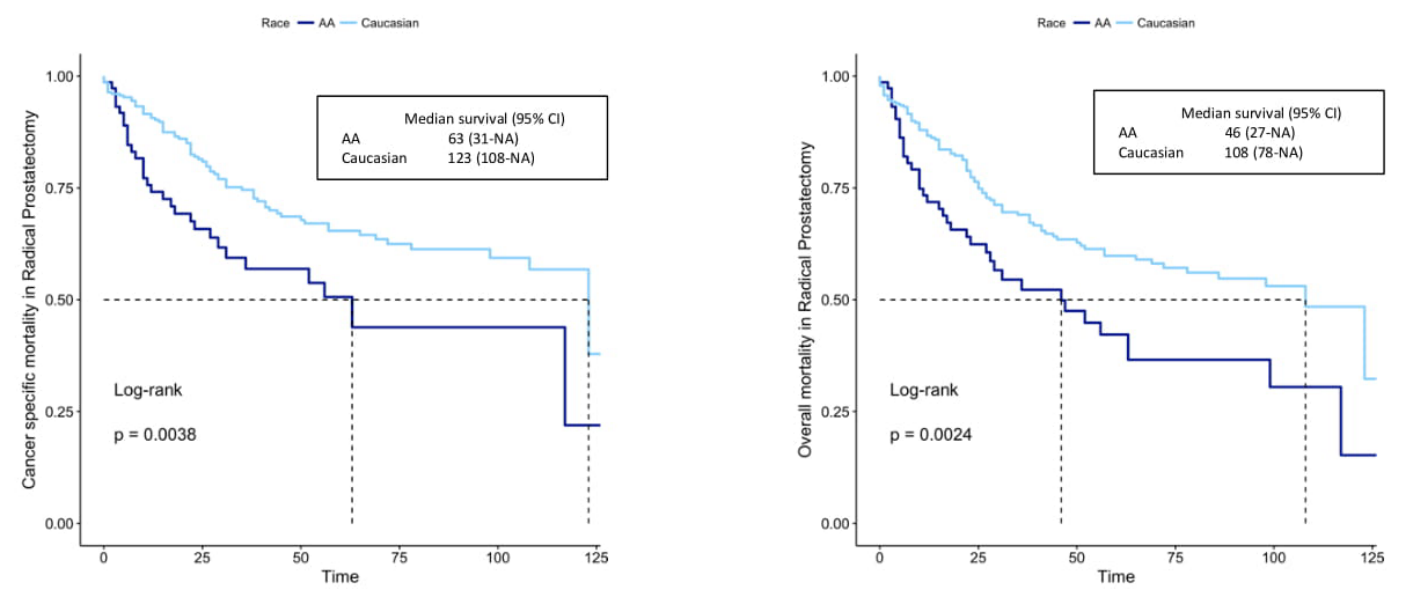

C
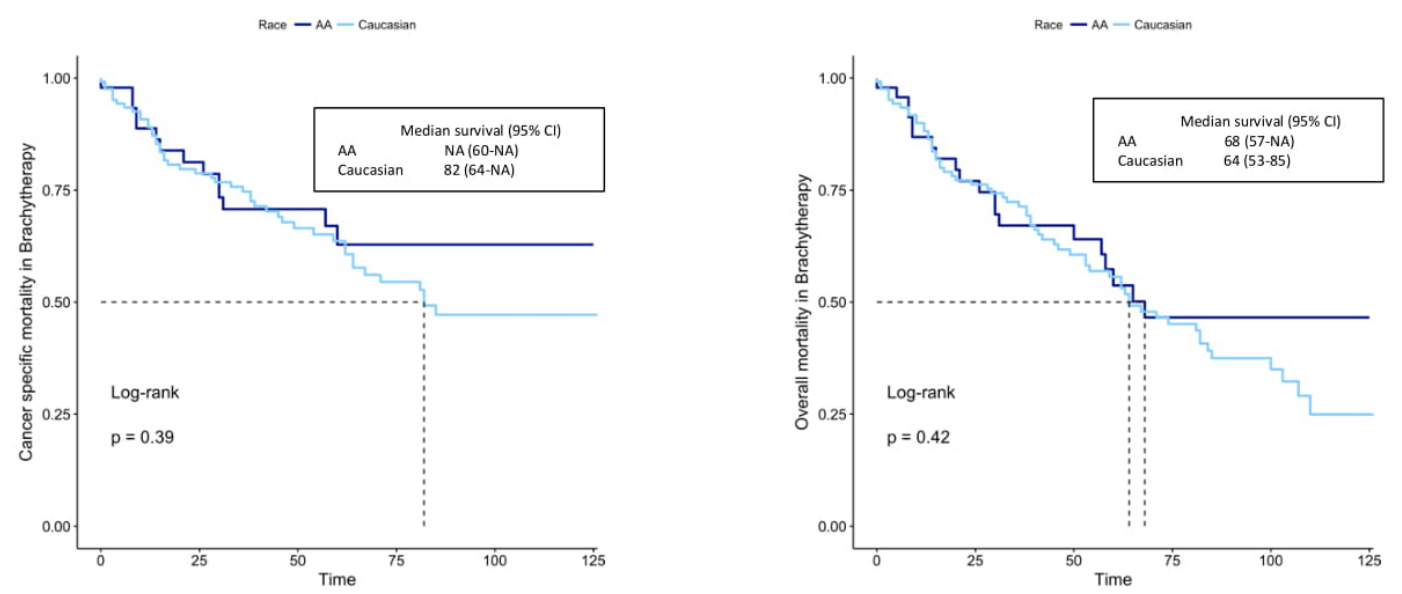


\begin{tabular}{|c|c|c|c|c|c|}
\hline Variable & & $\begin{array}{c}\text { Overall=529 } \\
(100 \%)\end{array}$ & $\begin{array}{l}\mathrm{AA}=121 \\
(22.8 \%)\end{array}$ & $\begin{array}{c}\text { Caucasian=408 } \\
(77.2 \%)\end{array}$ & $\mathbf{p}$ \\
\hline \multirow[t]{2}{*}{$\begin{array}{l}\text { Local therapy } \\
\text { type }\end{array}$} & Brachytherapy & 172 (32.5) & 47 (38.8) & 125 (30.6) & 0.1 \\
\hline & $\begin{array}{l}\text { Radical } \\
\text { Prostatectomy }\end{array}$ & 357 (67.5) & $74(61.2)$ & 283 (69.4) & \\
\hline Median PSA & Median, IQR & $14.3(6.3-58.7)$ & $18.2(7-98)$ & $13.4(6.3-45.2)$ & 0.018 \\
\hline Age at diagnosis & Median, IQR & $65(58-72)$ & $65(57-70)$ & 65 (59-72) & 0.3 \\
\hline \multirow[t]{4}{*}{$\begin{array}{l}\text { Gleason score } \\
\text { (biopsy) }\end{array}$} & $\leq 6$ & $133(25.1)$ & $30(24.8)$ & 103 (25.2) & 0.5 \\
\hline & 7 & $249(47.1)$ & $51(42.1)$ & 198 (48.5) & \\
\hline & $8-10$ & $55(10.4)$ & $15(12.4)$ & $40(9.8)$ & \\
\hline & Unknown & $92(17.4)$ & $25(20.7)$ & $67(16.4)$ & \\
\hline \multirow[t]{4}{*}{ Clinical T stage } & $<\mathrm{T} 2$ & $278(52.6)$ & 67 (55.4) & $211(51.7)$ & 0.47 \\
\hline & $\mathrm{T} 2$ & $165(31.2)$ & $39(32.2)$ & $126(30.9)$ & \\
\hline & T3 & $45(8.5)$ & $3(2.5)$ & $42(10.3)$ & \\
\hline & $\mathrm{T} 4$ & $41(7.8)$ & $12(9.9)$ & $29(7.1)$ & \\
\hline \multirow[t]{3}{*}{ Clinical N stage } & N0 & $225(42.5)$ & $68(56.2)$ & $157(38.5)$ & 0.002 \\
\hline & $\mathrm{N} 1$ & $76(14.4)$ & $14(11.6)$ & $62(15.2)$ & \\
\hline & NX & $228(43.1)$ & $39(32.2)$ & 189 (46.3) & \\
\hline \multirow[t]{4}{*}{ AJCC M1 stage } & M1a & $55(10.4)$ & $6(5)$ & $49(12)$ & 0.017 \\
\hline & M1b & $343(64.8)$ & $76(62.8)$ & 267 (65.4) & \\
\hline & M1c & $115(21.7)$ & $32(26.4)$ & $83(20.3)$ & \\
\hline & Unknown & $16(3)$ & $7(5.8)$ & $9(2.2)$ & \\
\hline \multirow[t]{3}{*}{ Marital status } & Married & $358(67.7)$ & $68(56.2)$ & $290(71.1)$ & $<0.001$ \\
\hline & Unmarried & $142(26.8)$ & $50(41.3)$ & $92(22.5)$ & \\
\hline & Unknown & $29(5.5)$ & $3(2.5)$ & $26(6.4)$ & \\
\hline \multirow[t]{11}{*}{ Year of diagnosis } & 2004 & $39(7.4)$ & $8(6.6)$ & $31(7.6)$ & 0.4 \\
\hline & 2005 & $42(7.9)$ & $7(5.8)$ & $35(8.6)$ & \\
\hline & 2006 & $48(9.1)$ & $15(12.4)$ & $33(8.1)$ & \\
\hline & 2007 & $43(8.1)$ & $12(9.9)$ & $31(7.6)$ & \\
\hline & 2008 & 47 (8.9) & $7(5.8)$ & $40(9.8)$ & \\
\hline & 2009 & $45(8.5)$ & $13(10.7)$ & $32(7.8)$ & \\
\hline & 2010 & $46(8.7)$ & $11(9.1)$ & $35(8.6)$ & \\
\hline & 2011 & $50(9.5)$ & $12(9.9)$ & $38(9.3)$ & \\
\hline & 2012 & $48(9.1)$ & $15(12.4)$ & $33(8.1)$ & \\
\hline & 2013 & $51(9.6)$ & $9(7.4)$ & $42(10.3)$ & \\
\hline & 2014 & $70(13.2)$ & $12(9.9)$ & $58(14.2)$ & \\
\hline
\end{tabular}

AA: African American; AJCC: American Joint Committee on Cancer; IQR: interquartile range; PSA: prostate-specific antigen. 


\begin{tabular}{|c|c|c|c|c|}
\hline Variables & $\begin{array}{c}\text { CSM, } \\
\text { HR (95\% CI) }\end{array}$ & $\mathbf{p}$ & $\begin{array}{c}\text { OM, } \\
\text { HR (95\% CI) }\end{array}$ & $\mathbf{p}$ \\
\hline \multicolumn{5}{|l|}{ Race } \\
\hline AA & REF & & REF & \\
\hline Caucasian & $\begin{array}{c}0.71 \\
(0.49-1.03)\end{array}$ & $\mathrm{p}=0.07$ & $\begin{array}{c}0.75 \\
(0.54-1.04) \\
\end{array}$ & $\mathrm{p}=0.09$ \\
\hline \multicolumn{5}{|l|}{ PSA } \\
\hline$<50$ & $\begin{array}{c}0.39 \\
(0.22-0.70) \\
\end{array}$ & $\mathrm{p}=0.002$ & $\begin{array}{c}0.38 \\
(0.23-0.63) \\
\end{array}$ & $\mathrm{p}<0.001$ \\
\hline 50-98 & REF & & REF & \\
\hline$>98$ & $\begin{array}{c}1.10 \\
(0.61-1.99) \\
\end{array}$ & $\mathrm{p}=0.7$ & $\begin{array}{c}0.93 \\
(0.55-1.57) \\
\end{array}$ & $\mathrm{p}=0.8$ \\
\hline \multicolumn{5}{|l|}{$\begin{array}{l}\text { Gleason score } \\
\text { (biopsy) }\end{array}$} \\
\hline$\leq 6$ & $\begin{array}{c}0.62 \\
(0.26-1.47) \\
\end{array}$ & $\mathrm{p}=0.3$ & $\begin{array}{c}0.60 \\
(0.30-1.20) \\
\end{array}$ & $p=0.1$ \\
\hline 7 & REF & & REF & \\
\hline $8-10$ & $\begin{array}{c}2.42 \\
(1.50-3.89) \\
\end{array}$ & $\mathrm{p}<0.001$ & $\begin{array}{c}1.84 \\
(1.24-2.74) \\
\end{array}$ & $\mathrm{p}=0.002$ \\
\hline Unknown & $\begin{array}{c}2.91 \\
(1.71-4.94) \\
\end{array}$ & $\mathrm{p}<0.001$ & $\begin{array}{c}2.33 \\
(1.49-3.64) \\
\end{array}$ & $\mathrm{p}<0.001$ \\
\hline \multicolumn{5}{|c|}{ Clinical T stage } \\
\hline$<\mathrm{T} 2$ & REF & & REF & \\
\hline $\mathrm{T} 2$ & $\begin{array}{c}0.89 \\
(0.61-1.29) \\
\end{array}$ & $\mathrm{p}=0.5$ & $\begin{array}{c}0.93 \\
(0.67-1.28) \\
\end{array}$ & $\mathrm{p}=0.6$ \\
\hline T3 & $\begin{array}{c}0.76 \\
(0.39-1.48)\end{array}$ & $\mathrm{p}=0.4$ & $\begin{array}{c}0.88 \\
(0.49-1.56)\end{array}$ & $\mathrm{p}=0.6$ \\
\hline $\mathrm{T} 4$ & $\begin{array}{c}2.46 \\
(1.52-3.97)\end{array}$ & $\mathrm{p}<0.001$ & $\begin{array}{c}2.19 \\
(1.42-3.40)\end{array}$ & $\mathrm{p}<0.001$ \\
\hline \multicolumn{5}{|c|}{ Clinical N stage } \\
\hline N0/NX & REF & & REF & \\
\hline N1 & $\begin{array}{c}0.62 \\
(0.37-1.05) \\
\end{array}$ & $\mathrm{p}=0.07$ & $\begin{array}{c}0.70 \\
(0.44-1.11) \\
\end{array}$ & $p=0.1$ \\
\hline \multicolumn{5}{|c|}{ AJCC M stage } \\
\hline M1a & REF & & REF & \\
\hline M1b & $\begin{array}{c}1.62 \\
(0.37-3.24) \\
\end{array}$ & $\mathrm{p}=0.1$ & $\begin{array}{c}1.70 \\
(0.94-3.07) \\
\end{array}$ & $\mathrm{p}=0.07$ \\
\hline M1c & $\begin{array}{c}2.09 \\
(1.01-4.31)\end{array}$ & $\mathrm{p}=0.045$ & $\begin{array}{c}1.85 \\
(0.99-3.46)\end{array}$ & $\mathrm{p}=0.05$ \\
\hline Unknown & $\begin{array}{c}1.39 \\
(0.47-4.08) \\
\end{array}$ & $\mathrm{p}=0.5$ & $\begin{array}{c}1.33 \\
(0.51-3.47) \\
\end{array}$ & $\mathrm{p}=0.5$ \\
\hline
\end{tabular}

AA: African American; AJCC: American Joint Committee on Cancer; CI: confidence interval; CSM: cancer-specific mortality; HR: hazard ratio; OM: overall mortality; PSA: prostate-specific antigen; REF: reference. ${ }^{*}$ Adjusted for age and marital status. 


\begin{tabular}{|c|c|c|c|c|}
\hline \multicolumn{5}{|c|}{$\begin{array}{l}\text { Table 3. Multivariable Cox regression models }{ }^{*} \text { predicting CSM and OM in patients with } \\
\text { newly diagnosed metastatic prostate cancer treated with radical prostatectomy }\end{array}$} \\
\hline \multirow[t]{2}{*}{ Variables } & \multicolumn{4}{|c|}{ Radical prostatectomy } \\
\hline & $\begin{array}{c}\text { CSM, } \\
\text { HR (95\% CI) }\end{array}$ & $\mathbf{p}$ & $\begin{array}{c}\text { OM, } \\
\text { HR (95\% CI) }\end{array}$ & $\mathbf{p}$ \\
\hline \multicolumn{5}{|l|}{ Race } \\
\hline $\mathrm{AA}$ & REF & & REF & \\
\hline Caucasian & $0.56(0.35-0.88)$ & $\mathrm{p}=0.01$ & $0.60(0.40-0.90)$ & $\mathrm{p}=0.01$ \\
\hline \multicolumn{5}{|l|}{ PSA } \\
\hline$<50$ & $0.39(0.19-0.77)$ & $\mathrm{p}=0.007$ & $0.43(0.23-0.80)$ & $\mathrm{p}=0.007$ \\
\hline $50-98$ & REF & & REF & \\
\hline$>98$ & $1.01(0.50-2.00)$ & $\mathrm{p}=0.9$ & $0.86(0.46-1.59)$ & $\mathrm{p}=0.6$ \\
\hline \multicolumn{5}{|l|}{$\begin{array}{l}\text { Gleason } \\
\text { score } \\
\text { (biopsy) }\end{array}$} \\
\hline$\leq 6$ & $0.64(0.17-2.40)$ & $\mathrm{p}=0.5$ & $0.57(0.18-1.75)$ & $\mathrm{p}=0.3$ \\
\hline 7 & REF & & REF & \\
\hline $8-10$ & $3.27(1.71-6.25)$ & $\mathrm{p}<0.001$ & $2.58(1.50-4.44)$ & $\mathrm{p}<0.001$ \\
\hline Unknown & 4.07 (1.98-8.39) & $\mathrm{p}<0.001$ & $3.18(1.50-5.88)$ & $\mathrm{p}<0.001$ \\
\hline \multicolumn{5}{|c|}{ Clinical T stage } \\
\hline$<\mathrm{T} 2$ & REF & & REF & \\
\hline $\mathrm{T} 2$ & 1.07 (0.67-1.70) & $\mathrm{p}=0.7$ & $1.09(0.72-1.65)$ & $\mathrm{p}=0.056$ \\
\hline T3 & $1.26(0.59-2.69)$ & $\mathrm{p}=0.5$ & $1.12(0.55-2.26)$ & $\mathrm{p}<0.001$ \\
\hline $\mathrm{T} 4$ & $3.08(1.72-5.51)$ & $\mathrm{p}<0.001$ & 2.55 (1.49-4.37) & $\mathrm{p}<0.001$ \\
\hline \multicolumn{5}{|l|}{$\begin{array}{l}\text { Clinical } \\
\mathrm{N} \text { stage }\end{array}$} \\
\hline N0/NX & REF & & REF & \\
\hline $\mathrm{N} 1$ & $0.49(0.27-0.88)$ & $\mathrm{p}=0.02$ & $0.64(0.23-1.06)$ & $\mathrm{p}=0.08$ \\
\hline \multicolumn{5}{|l|}{$\begin{array}{l}\text { AJCC } \\
\text { M stage }\end{array}$} \\
\hline M1a & REF & & REF & \\
\hline M1b & $1.14(0.50-2.60)$ & $\mathrm{p}=0.7$ & $1.25(0.61-2.57)$ & $\mathrm{p}=0.5$ \\
\hline M1c & $1.07(0.44-2.60)$ & $\mathrm{p}=0.9$ & $1.01(0.45-2.21)$ & $\mathrm{p}=0.9$ \\
\hline Unknown & $0.91(0.27-3.16)$ & $\mathrm{p}=0.9$ & $0.99(0.32-3.01)$ & $\mathrm{p}=0.9$ \\
\hline
\end{tabular}

AA: African American; AJCC: American Joint Committee on Cancer; CI: confidence interval; CSM: cancer-specific mortality; HR: hazard ratio; OM: overall mortality; PSA: prostate-specific antigen; REF: reference. ${ }^{*}$ Adjusted for age and marital status. 


\begin{tabular}{|c|c|c|c|c|}
\hline Variables & $\begin{array}{c}\text { CSM, } \\
\text { HR (95\% CI) }\end{array}$ & $\mathbf{p}$ & $\begin{array}{c}\text { OM, } \\
\text { HR }(95 \% \text { CI })\end{array}$ & $\mathbf{p}$ \\
\hline \multicolumn{5}{|l|}{ Race } \\
\hline AA & REF & & REF & \\
\hline Caucasian & $1.25(0.62-2.50)$ & $\mathrm{p}=0.5$ & $1.12(0.67-2.17)$ & $\mathrm{p}=0.5$ \\
\hline \multicolumn{5}{|l|}{ PSA } \\
\hline$<50$ & $0.42(0.13-1.35)$ & $\mathrm{p}=0.1$ & $0.35(0.12-0.99)$ & $\mathrm{p}=0.049$ \\
\hline $50-98$ & REF & & REF & \\
\hline$>98$ & $1.37(0.41-4.52)$ & $\mathrm{p}=0.6$ & $1.24(0.43-3.59)$ & $\mathrm{p}=0.6$ \\
\hline \multicolumn{5}{|l|}{$\begin{array}{l}\text { Gleason score } \\
\text { (biopsy) }\end{array}$} \\
\hline$\leq 6$ & $0.28(0.08-0.98)$ & $\mathrm{p}=0.048$ & $0.32(0.12-0.85)$ & $\mathrm{p}=0.02$ \\
\hline 7 & REF & & REF & \\
\hline $8-10$ & $1.35(0.62-2.93)$ & $\mathrm{p}=0.4$ & $0.97(0.51-1.86)$ & $\mathrm{p}=0.9$ \\
\hline Unknown & $1.27(0.53-3.01)$ & $\mathrm{p}=0.6$ & $1.17(0.57-2.39)$ & $\mathrm{p}=0.6$ \\
\hline \multicolumn{5}{|c|}{ Clinical T stage } \\
\hline$<\mathrm{T} 2$ & $\mathrm{REF}$ & & REF & \\
\hline $\mathrm{T} 2$ & $0.62(0.31-1.22)$ & $\mathrm{p}=0.2$ & $0.74(0.42-1.32)$ & $\mathrm{p}=0.3$ \\
\hline T3 & $0.19(0.03-0.91)$ & $\mathrm{p}=0.038$ & $0.48(0.15-1.47)$ & $\mathrm{p}=0.2$ \\
\hline $\mathrm{T} 4$ & $1.73(0.68-4.37)$ & $\mathrm{p}=0.2$ & $2.00(0.88-4.54)$ & $\mathrm{p}=0.1$ \\
\hline \multicolumn{5}{|c|}{ Clinical N stage } \\
\hline N0/NX & REF & & REF & \\
\hline N1 & $1.16(0.45-2.97)$ & $\mathrm{p}=0.7$ & $1.84(0.35-1.97)$ & $\mathrm{p}=0.7$ \\
\hline \multicolumn{5}{|c|}{ AJCC M stage } \\
\hline M1a & REF & & REF & \\
\hline M1b & $2.51(0.66-9.56)$ & $\mathrm{p}=0.1$ & $2.36(0.79-7.05)$ & $\mathrm{p}=0.1$ \\
\hline M1c & $4.58(1.12-18.6)$ & $\mathrm{p}=0.033$ & $3.64(1.15-11.5)$ & $\mathrm{p}=0.02$ \\
\hline Unknown & $1.83(0.16-20.6)$ & $\mathrm{p}=0.6$ & $1.09(0.11-10.9)$ & $\mathrm{p}=0.9$ \\
\hline
\end{tabular}

AA: African American; AJCC: American Joint Committee on Cancer; CI: confidence interval; CSM: cancer-specific mortality; HR: hazard ratio; OM: overall mortality; PSA: prostate-specific antigen; REF: reference. ${ }^{*}$ Adjusted for age and marital status. 